This is an author produced version of a paper published in URBAN WATER. This paper has been peer-reviewed but does not include the journal pagination

Citation for the published paper:

Persson, J. (2000) The Hydraulic Performance of Ponds of Various

Layouts. Urban Water. Volume: 2 Number: 3, pp 243-250.

http://dx.doi.org/10.1016/S1462-0758(00)00059-5

Access to the published version may require journal subscription.

Published with permission from: Elsevier Ltd.

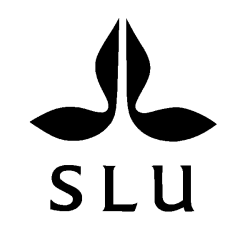

Epsilon Open Archive http://epsilon.slu.se 


\title{
The hydraulic performance of ponds of various layouts
}

\author{
J. Persson
}

\begin{abstract}
This study analyses how the hydraulic performance differs between 13 ponds with hypothetically different layouts. The paper also includes a discussion of short-circuiting, hydraulic efficiency and suitable parameters for measuring hydraulic performance. The ponds were studied by using a 2-D vertically integrated numerical model. Tracer studies were simulated and then evaluated and compared. The results confirm that length-to-width ratio, location of in- and outlets, and subsurface berm have a large impact on pond hydraulic performance. There is also an indication that an island placed in front of the inlet improves the hydraulic performance, and that a curved pond or an island placed near the side does not decrease the performance. (C) 2001 Elsevier Science Ltd. All rights reserved.
\end{abstract}

Keywords: Hydraulics; Layout; Hydraulic performance; Numerical simulation; Pond; Short-circuiting; Wetland

\section{Introduction}

\subsection{Ponds for improving water quality}

Constructed ponds and surface flow wetlands (SFW) are used to treat agricultural runoff, sewage and stormwater. The treatment of the first two types of water aims mainly at reducing nitrogen, carbon and phosphorus, while treatment of stormwater often aims at reducing the level of suspended solids. For such treatments, the hydraulics is a most important factor for high performance. Other factors such as vegetation, hydrological regime and organic loading are also considered as important. This has led to different design recommendations for improving the hydraulic performance and also ultimately for improving the water quality. In this study, numerical simulation is used to analyse the hydraulic performance of different pond layouts. This is also a valid approximation to SFW systems.

\subsection{Hydraulic performance and efficiency: a theoretical background}

Many authors (Brown, 1994; WPCF, 1990) claim that the importance of the hydraulic design of SFW systems cannot be overemphasised, and that short-circuiting is one of the greatest hindrances to successful pond design. Hydraulic efficiency can be described as how well the incoming water distributes within the pond (Wong \& Somes, 1995). All of the design models in current use assume uniform flow conditions and unrestricted opportunities for contact between the incoming water and the organisms responsible for treatment. It is also commonly known that this assumption is unrealistic (Reed, Crites, \& Middlebrooks, 1995).

The Water Pollution Control Federation (WPCF, 1990) describes optimal flow as a flow with uniform velocity profile. If there is a uniform velocity profile, the water packages move parallel, with no water movement sidewise. What the WPCF (1990) recommends is therefore that the ponds ought to have a plug flow, since such a flow is characterised as having a uniform velocity profile. However, flows with a uniform velocity profile exist only in ponds with a large length-to-width ratio. Generally, the pond water does not move homogeneously, but rather in eddies and with recirculation. Therefore, in practice, local velocity profiles or velocity vectors give limited information for the evaluation of the hydraulic performance compared to, e.g., tracer experiments.

Plug flow is generally considered to be the optimal flow and, from a hydraulic point of view, is the preferred flow regime since all fluid elements reside around the nominal residence. Further, the removal rate of BOD, 
TSS and TN increases with the loading rate (Knight, 1987), which makes plug flow more desirable.

A common method to study hydraulic performance is by using a tracer. By injecting a tracer instantaneously in the inlet and then measuring the outlet concentration, different water systems will produce different residence time distribution functions (RTD). The mean detention time (i.e., mean residence time), $t_{\text {mean }}$, which is the average time that a tracer particle spends in the water system, is defined as the centroid of the RTD, where the RTD function, $f(t)$, is represented by the concentration or mass

$t_{\text {mean }}=\frac{\int_{0}^{\infty} t f(t) \mathrm{d} t}{\int_{0}^{\infty} f(t) \mathrm{d} t}$.

Another fundamental expression is the variance, $\sigma^{2}$, which is a measure of the spread of the RTD. A plug flow condition will induce a RTD with a variance equalling 0 (i.e., no dispersion other than the advection)

$\sigma^{2}=\frac{\int_{0}^{\infty}\left(t_{\text {mean }}-t\right)^{2} f(t) \mathrm{d} t}{\int_{0}^{\infty} f(t) \mathrm{d} t}$.

A common measure of the degree of plug flow is the number of stirred tanks $(N)$ used in a tank-in-series model (Fogler, 1992). Higher the $N$, the more plug-flowlike the flow is. Measures of $N$ are

$N=\frac{t_{\mathrm{n}}^{2}}{\sigma^{2}}$,

where $t_{\mathrm{n}}$ is the nominal detention time (which is defined by the ratio between the volume and flow). The median detention time (often referred to as $t_{50}$ ) can in some cases be used as an approximation to the mean detention time. This is correct when the RTD is symmetrical (as in Gaussian functions), but is less suitable the more skewed the RTD becomes.

However, to consider only the degree of plug flow is not sufficient, since the effective volume differs considerably between ponds; i.e., the mean detention time, $t_{\text {mean }}$, is less than the nominal detention time, $t_{\mathrm{n}}$. The effective volume ratio, $e$, is defined by (Thackston, Shields, \& Schroeder, 1987)

$e=\frac{t_{\text {mean }}}{t_{\mathrm{n}}}=\frac{V_{\text {effective }}}{V_{\text {total }}}$,

where $V_{\text {total }}$ is the total volume of the water system and $V_{\text {effective }}$ is the total volume minus the dead volume (i.e., volume of water that has no interaction with the water flowing through the system).

As a measure of short-circuiting, the quotient $S$ is used, here defined as $t_{16}$ divided by the nominal detention time, $t_{\mathrm{n}}$, where $t_{16}$ is the time for passage of the 16th percentile through the outlet

$S=\frac{t_{16}}{t_{\mathrm{n}}}$.
The conclusion is therefore that low amounts of mixing and dead zones are two characteristics of hydraulic efficiency of ponds. In this study, however, the focus is on hydraulic performance and not efficiency. Performance is a wider concept that covers more aspects of the flow conditions (e.g., short-circuiting and lagtime) and is less value-oriented.

\subsection{Research on pond hydraulics}

Factors that influence the hydraulic performance in ponds are mainly related to shape, including baffles (Mangelson \& Watters, 1972; Thackston et al., 1987); topography (Somes, Bishop, \& Wong, 1997; Knight \& Iverson, 1990); vegetation (Moshiri, 1993; Somes et al., 1997; Kadlec, 1990); flow (Mangelson \& Watters, 1972; Adamsson, Persson, \& Lyngfelt, 1999); location of inand outlets (Mangelson \& Watters, 1972, Ta \& Brignal, 1998); wind (Shaw, Watt, Marsalek, \& Anderson, 1997; Kadlec \& Knight, 1996); and temperature (Marecos de Monte \& Mara, 1987; Torres, Soler, Saez, \& Ortuno, 1997). Other research efforts have focussed on defining hydraulic efficiency (Persson, Somes, \& Wong, 1999). In this study, however, the focus will be on shape and the location of in- and outlet.

Generally, the design recommendations related to hydraulic performance emphasize the relationship between pond length, width and depth, and also the location of in- and outlets with different configurations. Length-to-width ratio is generally seen as the most important factor influencing hydraulic performance. $\mathrm{Nu}$ merous researchers report this, and also recommend different ratios to achieve a low degree of mixing and short-circuiting (Watson \& Hobson, 1989; WPCF, 1990; Crites, 1994). Thackston et al. (1987) recommend, for example, an $L / W$ ratio of $5-10: 1$, while Reed et al. (1995) recommend a ratio of $1-4: 1$ in a well-designed system. The only reference found to disagree with this is Kadlec and Knight (1996) who state that form does not have much effect on hydraulic performance (due to wind mixing effects).

As will be discussed later, Thackston et al. (1987) developed an equation for calculating the effective volume, $e$, for basins

$e=0.84\left[1-\mathrm{e}^{(-0.59 L / W)}\right]$,

where $L$ is the length and $W$ is the width of the pond.

For basins, Nameche and Vasel (1998) suggest that the Peclet number, which is determined by the degree of mixing in a system, can be expressed as

$P e=0.35 \frac{L}{W}+0.012 \frac{L}{Z}$,

where $L, W$ and $Z$ are the pond length, width and depth, respectively. Eq. (7) clearly shows the importance of the 
length-to-width ratio and that it not only influences the effective volume ratio but also the dispersion.

Matthews, Watt, Marsalek, Gowder, and Anderson (1997) carried out several tracer experiments on a stormwater pond $\left(4600 \mathrm{~m}^{2}\right)$, where the length-to-width ratio was changed from $1.5: 1$ to $4.5: 1$. The results showed that an increasing ratio increases the mean detention time and also the amount of effective volume.

The other design recommendation concerns the location of in- and outlets, also with different configurations. Ta and Brignal (1998) investigated an existing reservoir (of $200000 \mathrm{~m}^{3}$ ) with a computational fluid dynamics model (CFD). The results showed that a submerged baffle or manifold inlet configuration made the flow become less mixed and with less short-circuiting.

\subsection{Aim of the study}

The present aim is to analyse, with $2-\mathrm{D}$ vertically integrated numerical simulation, how hydraulic performance differs between hypothetical ponds with different layouts. By investigating 13 different layouts, this study relates to research which states that:

- an increasing length-to-width ratio increases the mean detention time and the amount of effective volume, and decreases the amount of mixing;

- this is also the case when a subsurface berm or a manifold inlet configuration is introduced.

It also investigates the impact of:

- a small island;

- a curved geometry;

- different locations of in- and outlets.

The focus in most of the studies carried out in this still limited research area is on waste stabilisation ponds. The questions behind this paper originate rather from the growing interest in water quality ponds in rural and urban areas that, at least in Sweden, impose demands of aesthetic value. These ponds therefore have irregular shape and topography, which make the hydraulic performance more difficult to predict.

\section{Methods}

\subsection{The cases studied}

The chosen layouts were based on a literature review of pond design (Persson, 1998). Normally, design varies according to length-to-width ratio, shape, topography (islands and subsurface berms), and location of in-/ outlets. These criteria thus became the point of departure of the study. In Sweden, ponds and SFW are used to treat runoff from agricultural land, stormwater and sewage water. Generally such ponds have a depth be-
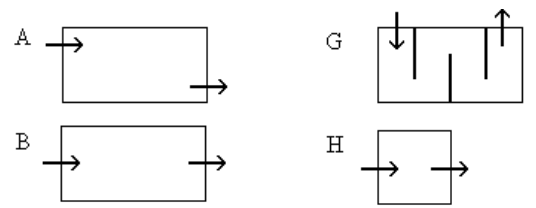

$\mathrm{H}$
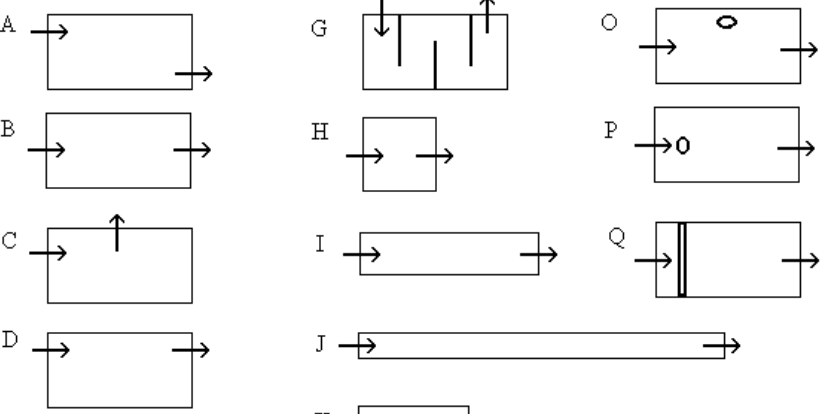

$\mathrm{J}$
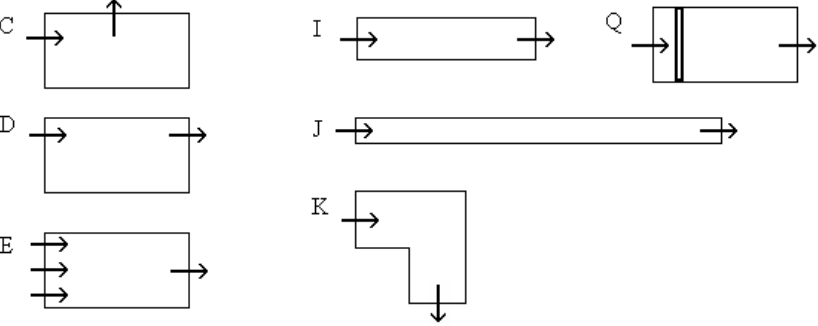

Fig. 1. The 13 cases studied.

tween 0.5 and $2 \mathrm{~m}$ and a surface area between 100 and $10,000 \mathrm{~m}^{2}$.

To minimise possible scale effects, all simulated ponds had approximately the same volume $\left(2700 \mathrm{~m}^{3}\right)$ and depth $(1.5 \mathrm{~m})$. The basic shape was a rectangular pond with the length-to-width ratio of $2: 1$. The length-towidth ratio was then changed to $1: 1,4: 1$ and $12: 1$. One case consists of the basic shape but with three baffles, increasing the ratio to approximately 8:1. The shape was rectangular in all the 13 cases except one, which had an L-shape. In three cases, an island or a subsurface berm changed the topography. The berm had a height of 1.1 $\mathrm{m}$, placed $0.4 \mathrm{~m}$ below the surface. The in- and outlets differed according to location. Fig. 1 shows the 13 cases. Parameters not taken into account were wind and temperature conditions (no wind or thermal stratification was therefore assumed). The ground and air conditions were not taken into account either, in the sense that no leakage, inflow or evaporation were assumed.

\subsection{Model setup and simulations}

The model used, Mike21, is a 2-D CFD that was developed by the Danish Hydraulic Institute (DHI). The 2-D model utilises a depth-integrated approach assuming that the water mass is vertically homogeneous. This is well suited to a pond, which normally has a depth of around $0.5-2 \mathrm{~m}$. The model is, however, a general numerical modelling system for the simulation of water levels and flows in estuaries, bays and coastal areas. The equations in Mike21 can be derived from the basic Navier-Stokes formulation integrating over the depth. In this study, two of the Mike21 modules were used: the hydrodynamic (HD) and the advection-dispersion (AD). The main inputs in the HD module are bathymetry, simulation period, timestep, inflow and, in the AD module, component description, inlet boundary concentration and dispersion coefficients. 
The effective shear stresses in the momentum equations contain momentum fluxes that come from turbulence, vertical integration and subgrid scale fluctuations. Using an eddy viscosity formulation, which in this study was based on velocity gradients, includes these terms. The turbulence was calculated from Smagorinsky's concept, assuming it to be a function of a constant $C_{\mathrm{s}}$ (varying from 0.25 to 1.0 ), gridspace and the depth-integrated velocity gradients in $x$ - and $y$-directions. In this study, the constant was set to 1 and the gridspace to $2 \mathrm{~m}$. The dispersion coefficient was set to $0.0005 \mathrm{~m}^{2} / \mathrm{s}$ in $x$ and $0 \mathrm{~m}^{2} / \mathrm{s}$ in $y$-directions. The flow was constantly $40 \mathrm{l} /$ $\mathrm{s}$ in all the simulations.

The simulations have not been verified on existing ponds, but this is not crucial, since the focus is on the difference between layouts among hypothetical cases, not on calibration of the numerical model or study of existing ponds. However, in a parallel study carried out at the department, simulations and validation have been performed on a large-scale basin $\left(13 \times 9 \times 1 \mathrm{~m}^{3}\right)$ to test the numerical model used in this study (Adamsson et al., 1999).

It can be added that 3-D and vertically integrated 2-D models have been used in several studies for analysing pond hydraulics. Adamsson et al. (1999) used 2-D (vertically integrated) and 3-D models simulating the flow in a basin. Benelmouffok and Yu (1989) used a vertically integrated 2-D model on a large detention pond. Among those who used vertically integrated 2-D models, it was concluded that it was possible to simulate the flow conditions in ponds, provided that the flow did not contain larger 3-D effects like stratified flow or complex topography. But numerical simulations have also been used to test possible hydraulic improvements by adding design elements such as baffles or changing vegetation and outlet configuration. Some examples are given in Wood, Greenfield, Howes, Johns, and Keller (1995), Somes et al. (1997) and Ta and Brignal (1998).

\section{Results}

The results of the computer simulations are shown in Table 1 and, as an example of the simulated RTD, four cases are shown in Fig. 2. Those cases which had high $S$ value (i.e., small short-circuiting effects) were ponds with high length-to-width ratios (cases $\mathbf{J}$ and $\mathbf{G}$ ) and the case which had an inlet along the whole base (case E). Further, it was noticed that if an island or a subsurface berm was placed in front of the inlet (cases P and Q) the $S$ value increased by $100 \%$ compared to the basic shape. Those cases that had a small $S$-value were thus, of course, the shapes with small length-to-width ratio (case $\mathrm{H})$, where the in- and outlets were placed close to each other (case C), and then the in- and outlets were placed in the upper corners (case D).

In several cases (E, G, I, J, P, Q), the effective volume was around $90-100 \%$. This was the case especially where ponds had high length-to-width ratios, but it was also notable when an island or a subsurface berm was placed in front of the inlet. As with short-circuiting, low effec-

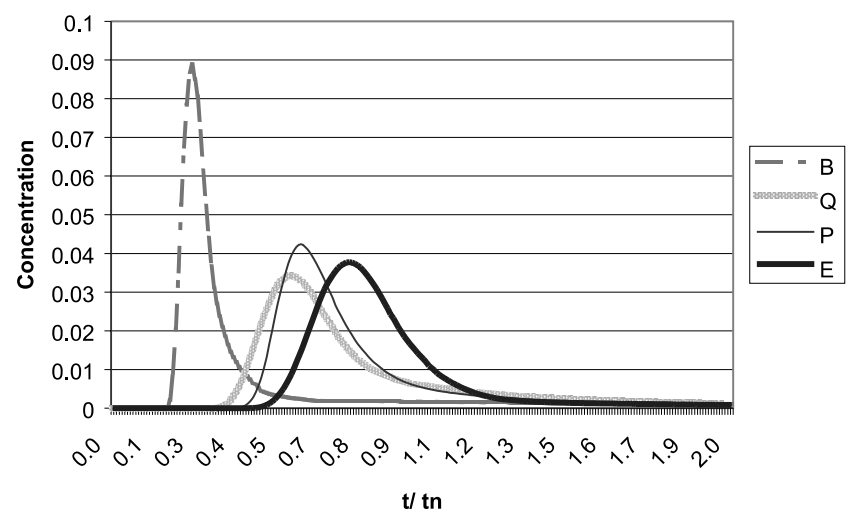

Fig. 2. The RTD for cases B, Q, P and E, as an example. The time-axis is normalised with the nominal detention time.

Table 1

Nominal detention time $\left(t_{\mathrm{n}}\right), 16$ th percentile, median detention time (50th percentile), variance $\left(\sigma^{2}\right)$, mean detention time $\left(t_{\text {mean }}\right)$, short-circuiting $(S)$, effective volume $(e)$ and the number of stirred tanks $(N)$ in the 13 simulated cases

\begin{tabular}{|c|c|c|c|c|c|c|c|c|}
\hline Case & $t_{\mathrm{n}}(\mathrm{h})$ & $t_{16}(\mathrm{~h})$ & $t_{50}(\mathrm{~h})$ & $t_{\text {mean }}(\mathrm{h})$ & $\sigma^{2}\left(h^{2}\right)$ & $S$ & $e$ & $N$ \\
\hline A & 18.8 & 5.48 & 7.57 & 13.9 & 266 & 0.29 & 0.74 & 0.73 \\
\hline B & 18.8 & 4.50 & 5.83 & 14.8 & 359 & 0.24 & 0.79 & 0.61 \\
\hline $\mathrm{C}$ & 18.8 & 1.83 & 2.25 & 8.62 & 264 & 0.10 & 0.46 & 0.28 \\
\hline D & 18.8 & 3.00 & 3.57 & 6.39 & 81.4 & 0.16 & 0.34 & 0.50 \\
\hline E & 18.8 & 12.7 & 15.4 & 16.8 & 34.6 & 0.68 & 0.89 & 8.2 \\
\hline $\mathrm{G}$ & 17.3 & 12.5 & 16.0 & 17.3 & 28.2 & 0.72 & 1.0 & 11 \\
\hline $\mathrm{H}$ & 18.4 & 1.77 & 2.17 & 8.14 & 284 & 0.10 & 0.44 & 0.23 \\
\hline I & 18.8 & 9.34 & 15.3 & 19.1 & 220 & 0.50 & 1.0 & 1.7 \\
\hline J & 14.8 & 12.9 & 14.4 & 15.2 & 6.70 & 0.87 & 1.0 & 34 \\
\hline $\mathrm{K}$ & 20.0 & 6.87 & 9.83 & 15.5 & 213 & 0.34 & 0.78 & 1.1 \\
\hline $\mathrm{O}$ & 18.3 & 4.60 & 5.63 & 13.3 & 113 & 0.25 & 0.73 & 1.6 \\
\hline $\mathrm{P}$ & 18.5 & 10.6 & 13.1 & 17.7 & 146 & 0.57 & 0.96 & 2.1 \\
\hline Q & 18.3 & 9.17 & 12.9 & 17.0 & 288 & 0.50 & 0.93 & 1.0 \\
\hline
\end{tabular}


tive volume could be found in cases $\mathrm{H}, \mathrm{C}$ and $\mathrm{D}$. It should be emphasised that the location of in- and outlets has a considerable influence on the amount of effective volume. In relation to the basic case (B) with $79 \%$ effective volume, this may be reduced to $34-46 \%$ when the outlet is badly located.

The amount of mixing is highly affected by the lengthto-width ratio. Cases $J$ and $G$ showed plug flow conditions, while case $\mathrm{H}$ had large mixing flow. An island or a subsurface berm that was placed in front of the inlet decreased the amount of mixing, but not as much as the case that had an inlet along the whole base (E).

The variance seems to be very large in relation to the mean detention time. The probable explanation for this is the long tail of the RTD, which is common in systems with large dispersion. However, a contribution to the high variance and also the high mean detention times may have an explanation in the numerical simulations, which have not been calibrated to any existing system.

\section{Discussion}

\subsection{Length-to-width ratio}

Plug flow condition is generally preferred because the mass removal rate increases with increasing mass loading rate (Knight, 1987). This condition is strongly correlated to high length-to-width ratio. However, the cost of construction increases with increasing length-towidth ratios. Knight's conclusion, after analysing these costs and benefits, is that the most optimal length-towidth ratio is 2:1. However, according to Reed et al. (1995), it has been a tradition to assume that ratios of at least 10:1 are needed to ensure plug flow. Reed et al. (1995) maintain that a major problem with this approach is that the resistance to flow increases as the length of the flow path increases, which in the end can lead to overflow. Reed et al. (1995) recommend lengthto-width ratios from less than $1: 1$ up to about $3-4: 1$. Problems such as short-circuiting should instead be minimised by careful construction, maintenance of the bottom, use of multiple cells, and intermediate openwater zones for flow redistribution.

As expected, this study showed that a higher lengthto-width ratio makes a flow more similar to plug flow; see Table 2. Case G, a folded shape, gave an hydraulic performance similar to a straightened-out pond. The folded case had the length-to-width ratio 2:1, but with three baffles. If the pond had been straightened out, the ratio would have been about 8:1 instead. Also, the shortcircuiting decreases with increasing length-to-width ratio (since high $S$-values represent low short-circuiting). The effective volume increases with increasing length-towidth ratio.
Table 2

$S, \sigma$ and $N$ in five cases with different length-to-width ratios

\begin{tabular}{lllll}
\hline Case & Length-to-width ratio & $S$ & $e$ & $N$ \\
\hline H & $1: 1$ & 0.10 & 0.44 & 0.23 \\
B & $2: 1$ & 0.24 & 0.79 & 0.61 \\
I & $4: 1$ & 0.50 & 1.0 & 1.7 \\
G & $2: 1$ (folded pond) & 0.72 & 1.0 & 11 \\
J & $12: 1$ & 0.87 & 1.0 & 34 \\
\hline
\end{tabular}

\subsection{Subsurface berms}

In literature on pond/SFW design, it is sometimes suggested to use subsurface berms or deep zones (Knight \& Iverson, 1990) perpendicular to the flow, to improve the distribution of the incoming water. Leonardson (1994) has suggested a construction with subsurface berms which are placed perpendicular to the flow. These berms are built so that vegetation can be established upon them. The author emphasised, however, that the vegetation must not become too dense, as this can create canals, which decrease the distribution. One side-effect is also that the pond acquires a larger area of vegetation, which promotes reduction of pollutants.

This study showed that a subsurface berm decreases the short-circuiting, increases the effective volume and decreases the amount of mixing (see Table 3). It does not, however, give the same effect as case E, which had an inlet along the whole base. It should be interesting to investigate the effect of several subsurface berms. Probably, the result will show a decreasing effective volume and amount of mixing. This type of simulation will preferably be carried out with a 3-D model, since the complex topography will add 3-D effects on the flow.

\subsection{Islands}

An island (approximately $2 \%$ of the pond area) was placed near the side $(\mathrm{O})$ to see what effect it had on the hydraulics. The result was that it did not alter the detention time, effective volume or short-circuiting compared with the basic pond (B). However, the amount of mixing decreased. An island near the inlet $(\mathrm{P})$ resulted in

Table 3

$S$-, $e$ - and $N$-values for cases B, E and Q

\begin{tabular}{llll}
\hline Case & $S$ & $e$ & $N$ \\
\hline $\begin{array}{l}\text { B. Basic shape (2:1) } \\
\begin{array}{l}\text { E. Basic shape with inlet } \\
\text { along the whole base }\end{array}\end{array}$ & 0.24 & 0.79 & 0.61 \\
$\begin{array}{l}\text { Q. Subsurface berm in front } \\
\text { of the inlet }\end{array}$ & 0.50 & 0.93 & 1.0 \\
\hline
\end{tabular}


considerably less short-circuiting and mixing. The effective volume also increased. See Table 1.

\subsection{In- and outlets}

Five ponds with the same basic shape but with different in- and outlets were studied. Cases A and B had similar hydraulic performance. Cases $\mathrm{C}$ and $\mathrm{D}$, however, differed considerably from the basic shape $\mathrm{B}$, since they both showed more short-circuiting and less effective volume. In pond $\mathrm{C}$, some of the tracer went through quickly while some stayed for a longer time in the pond, with a long tail as a result. This can also be seen in the low median detention time of $2.25 \mathrm{~h}$ and a variance of 264. The pond that deviated most was E, which had an inlet along the whole base. Not surprisingly, this made the flow closer to plug flow. It also had less short-circuiting and larger effective volume than the basic case (B); see Fig. 2 and Table 1.

\subsection{L-shape}

For aesthetic reasons, it is not unusual that ponds have an L-shaped design. In this study, the L-shaped pond $(\mathrm{K})$ did not, however, differ much from the basic shape, which indicates that it is possible to curve the pond to accomplish a more suitable aesthetic shape without decreasing the hydraulic performance.

\subsection{Limitations and comments}

The design recommendations that are drawn from this study are to be regarded as general since no local characteristics, wind or vegetation are considered. Further considerations should probably be added when designing stormwater ponds, since these have fluctuating flow. The conducted simulations presumed constant flow, which is not as representative for ponds receiving stormwater as ponds receiving agricultural runoff or wastewater. Research carried out by Adamsson et al. (1999) also indicates that the amount of flow is a factor that changes the hydraulic performance.

\section{Previous research}

\subsection{Short-circuiting parameter}

Ta and Brignal (1998) have chosen a parameter based on the relation between $t_{16}$ and $t_{50}$ to measure the shortcircuiting. This, however, does not represent the effect when some tracer goes quickly from the inlet to the outlet, in relation to the pond volume. In this case, it is better to choose relationships such as $t_{16} / t_{\mathrm{n}}$ or $t_{10} / t_{\mathrm{n}}$,

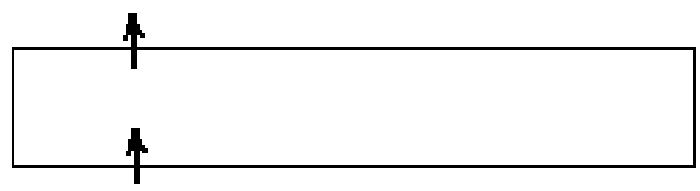

Fig. 3. Example of a pond with a combination of plug flow and shortcircuiting.

which the American Water Works Association. (1996) recommends. What the quotient $t_{16} / t_{50}$ represents is only the skewness in the RTD function. It is, e.g., not appropriate to use the ratio $t_{16} / t_{50}$ when in- and outlets are placed close to each other (as in case $\mathrm{C}$ which has both a small difference between $t_{16}$ and $t_{50}$ and a large variance). Another case is when the pond has a large ineffective volume and the flow is sparsely mixed. In this case, although the quotient $t_{16} / t_{50}$ is close to 1 , short-circuiting occurs; see Fig. 3. Table 4 shows calculations carried out according to the different definitions of short-circuiting.

\subsection{Length-to-width ratio}

Thackston et al. (1987) carried out an extensive study, investigating 12 ponds (shallow basins) with dye tracer. Most of the ponds were rectangular with $L / W$ ratios varying from 0.7 to 4.1 . The inlet generally consisted of a single pipe and the outlet of an overflow weir at the opposite end. The aim of the work was to arrive at a method for predicting hydraulic efficiency based on design variables such as site geometry, discharge and expected wind conditions. To calculate the effective volume, $e$, Thackston et al. recommend Eq. (6).

Comparisons with Thackston's results show some similarities; see Table 5. It is not possible to compare the results fully, since Thackston's results are based on field measurements, while the tracer tests in this study derive from CFD modelling and are to be seen as a relative comparison between different layouts. Further, the hypothetical ponds in the CFD model are not calibrated with data from any existing pond. However, there is a relationship between an increasing $L / W$ ratio and an increasing effective volume. Mangelson and Watters (1972) also showed this by experimenting, with tracer, on scale models of waste stabilisation ponds (see Table 5). The results from this study and Thackston are relatively close to Eq. (6). Irregular pond geometry and wind can explain why some results of the field measurements differ from the calculated ones obtained with Eq. (6).

\subsection{Manifold inlet}

Compared to, e.g., Matthews et al., (1997) and Ta and Brignal (1998), this study used a considerably larger number of cases. However, Ta and Brignal's results 
Table 4

The short-circuiting measured in two different ways

\begin{tabular}{|c|c|c|c|c|c|c|c|c|c|c|c|c|c|}
\hline Case & A & B & $\mathrm{C}$ & $\mathrm{D}$ & $\mathrm{E}$ & $\mathrm{G}$ & $\mathrm{H}$ & I & $\mathrm{J}$ & $\mathrm{K}$ & $\mathrm{O}$ & $\mathrm{P}$ & $\mathrm{Q}$ \\
\hline$S=t_{16} / t_{50}$ & 0.72 & 0.77 & 0.81 & 0.84 & 0.82 & 0.78 & 0.82 & 0.81 & 0.90 & 0.70 & 0.86 & 0.81 & 0.71 \\
\hline$S=t_{16} / t_{\mathrm{n}}$ & 0.29 & 0.24 & 0.10 & 0.16 & 0.68 & 0.72 & 0.10 & 0.50 & 0.87 & 0.34 & 0.25 & 0.57 & 0.50 \\
\hline
\end{tabular}

Table 5

The length-to-width ratio and the effective volume $(e)$ calculated both from tracer results and by Eq. (7), for the cases in this study compared with the ponds investigated in Mangelson and Watters (1972) and Thackston et al. (1987)

\begin{tabular}{|c|c|c|c|}
\hline Pond & Length-to-width ratio & $\begin{array}{l}\text { Effective volume, } e \text { calculated by } \\
\text { tracer in field or CFD model }\end{array}$ & $\begin{array}{l}\text { Effective volume, } e \text {, cal- } \\
\text { culated by Eq. (7) }\end{array}$ \\
\hline (11) Thackston et al. (1987) & $1.6: 1$ & 0.22 & 0.51 \\
\hline (12) Thackston et al. (1987) & $2: 1$ & 0.51 & 0.58 \\
\hline (8) Thackston et al. (1987) & $3.4: 1$ & 1.0 & 0.73 \\
\hline (1) Thackston et al. (1987) & $4: 1$ & 0.73 & 0.77 \\
\hline (O-4) Mangelson and Watters (1972) & $2: 1$ & 0.456 & 0.58 \\
\hline (C-3) Mangelson and Watters (1972) & $13: 1$ & 0.931 & 0.84 \\
\hline Case $\mathrm{H}$ & $1: 1$ & 0.44 & 0.37 \\
\hline Case B & $2: 1$ & 0.79 & 0.58 \\
\hline Case I & $4: 1$ & 1.0 & 0.77 \\
\hline Case $\mathrm{G}$ & $8: 1$ ( $2: 1$ folded pond) & 1.0 & 0.83 \\
\hline Case $\mathbf{J}$ & $12: 1$ & 1.0 & 0.84 \\
\hline
\end{tabular}

a Among the 12 ponds investigated by Thackston, the two ponds with the largest and smallest $L / W$ ratios are shown here. The calculated effective volumes for the cases in this study are in italics, since the results from the model are not calibrated.

showed that a submerged baffle or manifold inlet configuration made the flow become less mixed and with less short-circuiting, which were also the conditions in cases Q and E.

\section{Conclusions}

The most significant results related to design recommendations indicate that a subsurface berm or an island placed in front of the inlet improves the hydraulic performance concerning short-circuiting, effective volume and amount of mixing. These design elements could therefore be recommended to increase ponds' hydraulic performance, while not having to increase the length-towidth ratio or the velocity of the water.

Further, the study showed that a curved pond or an island placed near the side does not lead to lower hydraulic performance, and that the length-to-width ratio and the locations of in- and outlets have a considerable impact on the hydraulic performance.

In some literature, short-circuiting is measured by the ratio between $t_{16}$ and $t_{50}$, which are the times for passage of the 16th and 50th percentiles through the outlet. In this study, it is recommended that $t_{50}$ be replaced with the nominal detention time.

\section{Acknowledgements}

The author wishes to thank the Swedish Council for Building Research (BFR), The Swedish Association of Graduate Engineers (CF), Swedish Foundation for Strategic Environmental Research (MISTRA) and the Danish Hydraulic Institute (DHI).

\section{References}

Adamsson, A., Persson, J., \& Lyngfelt, S. (1999). Numerical simulation and large-scale physical modelling of flow in a detention basin. Proceedings of the Eighth International Conference on Urban Storm Drainage, 30 August-3 September 1999, Sydney, Australia.

American Water Works Association. (1996).Tracer studies in water treatment facilities: A protocol and case studies, 2P-2.5C-90692-8/ 97-CM, USA: Denver.

Benelmouffok, D. E., \& Yu, S. L. (1989). Two-dimensional numerical modeling of hydrodynamics and pollutant transport in a wet detention pond. Water Science and Technology, 21, 727-738.

Brown, D. S. (1994). Constructed wetlands in the USA.Water Quality Instrumentation, 4, 24-28.

Crites, R. W. (1994). Design criteria and practice for constructed wetlands. Water Science and Technology, 29(4), 1-6.

Fogler, H. S. (1992). Elements of chemical reaction engineering (2nd ed.) (pp. 838). Englewood Cliffs, NJ: Prentice-Hall.

Kadlec, R. (1990). Overland flow in wetlands: vegetation resistance. Journal of Hydraulic Engineering, 116(5), 691-705. 
Kadlec, R., \& Knight, R. (1996). Treatment Wetlands. Chelsea, Michigan, USA: Lewis Publishers.

Knight, R. L. (1987). Effluent distribution and basin design for enhanced pollutant assimilation by freshwater wetlands. In Reddy K. R., W. H. Smith (Eds.), Aquatic plants for water treatment and resource recovery (pp. 913-921). Orlando, Florida, USA: Magnolia Publishing Company.

Knight, R. L., \& Iverson, M. E. (1990). Design of the fort deposit, Alabama, constructed wetlands treatment system. In: P. F. Cooper, \& B. C. Findlater (Eds.), Constructed wetlands in water pollution control. Proceedings of the international conference on the use of constructed wetlands in water pollution control (pp. 521524). Cambridge, UK, 24-28 September, Oxford, UK: Pergamon Press.

Leonardson, L. (1994). Wetlands as nitrogen sinks. Swedish and international experience, Naturvårdsverket Rapport 4176, Stockholm, Sweden (in Swedish with English summary).

Mangelson, K. A., \& Watters, G. Z. (1972). Treatment efficiency of waste stabilization ponds. Journal of Sanitary Engineering Division, American Society of Civil Engineering, 98.

Marecos de Monte, M. H. F., \& Mara, D. D. (1987). The hydraulic performance of waste stabilization ponds in Portugal. Water Science and Technology, 19(12), 219-227.

Matthews, R. R., Watt, W. E., Marsalek, J., Gowder, A. A., \& Anderson, B. C. (1997). Extending retention times in a stormwater pond with retrofitted baffles. Journal of Water Quality Research, Canada 32(1), 73-87.

Moshiri, G. A. (1993). Constructed wetlands for water quality improvement. Chelsea, Michigan, USA: Lewis Publishers.

Nameche, T. H., \& Vasel, J. L. (1998). Hydrodynamic studies and modelization for aerated lagoons and waste stabilization ponds. Water Science and Technology, 32(10), 3039-3045.

Persson, J. (1998). Pond design: A literature review with comments on stormwater ponds, and ponds receiving sewage and agriculture runoff (2nd ed.). Institutionen för Vattenbyggnad, Rapport B:64, Chalmers Tekniska Högskola, Sweden (in Swedish with English summary).
Persson, J., Somes, N. L. G., \& Wong, T. H. F. (1999). Hydraulic efficiency of constructed wetlands and ponds. Water science and technology, 40(3), 291-299.

Reed, S. H., Crites, R. W., \& Middlebrooks, E. J. (1995). Natural systems for waste management and treatment (2nd ed.). New York: McGraw-Hill.

Shaw, J. K. E., Watt, W. E., Marsalek, J., \& Anderson, B. C. (1997). Flow pattern characterization in an urban stormwater detention pond and implications for water quality. Journal of Water Quality Research, Canada 32(1), 53-71.

Somes, N. L. G., Bishop, W., \& Wong, T. H. F. (1997). Numerical simulations of wetland hydrodynamics. Modsim97 (pp. 385-390), Hobart, Australia.

Ta, C. T., \& Brignal, W. J. (1998). Application of computational fluid dynamics technique to storage reservoir studies. Water Science and Technology, 37(2), 219-226.

Torres, J. J., Soler, A., Saez, J., \& Ortuno, J. F. (1997). Hydraulic performance of a deep wastewater stabilization pond. Water Research, 31(4), 679-688.

Thackston, E. L., Shields, Jr., F. D., \& Schroeder, P. R. (1987). Residence time distributions of shallow basins. Journal of Environmental Engineering, 113(6), 1319-1332.

Watson, J. T., \& Hobson, J. A. (1989). Hydraulic design considerations and control structures for constructed wetlands for wastewater treatment. In D. A. Hammer (Ed.), Constructed wetlands for wastewater treatment municipal industrial and agricultural. Chelsea, Michigan, USA: Lewis Publishers.

Wood, M. G., Greenfield, P. F, Howes, T., Johns, M. R., \& Keller, J. (1995). Computational fluid dynamic modelling of wastewater ponds to improve design. Water Science and Technology, 31(12), $111-118$.

Wong, T. H. F., \& Somes, N. L. G. (1995). A stochastic approach to designing wetlands for stormwater pollution control. Water science and technology, 32(1), 145-151.

Water Pollution Control Federation. (1990). Manual of Practice, Natural Systems, Wetlands Chapter, February 1990, MOP FD-16 WPCF, 270-, USA. 